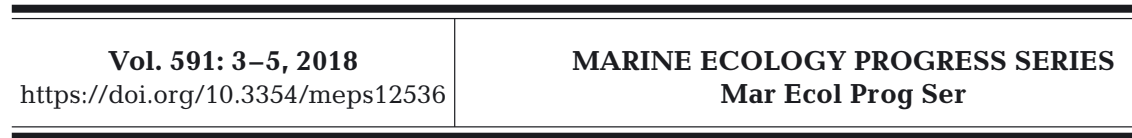

Contribution to the Theme Section 'Jellyfish bloom research: advances and challenges'

\title{
INTRODUCTION
}

\section{Jellyfish blooms: advances and challenges}

\author{
Verónica L. Fuentes ${ }^{1, *}$, Jennifer E. Purcell ${ }^{2}$, Robert H. Condon ${ }^{3}$, Fabien Lombard ${ }^{4}$, \\ Cathy H. Lucas ${ }^{5}$
}

\author{
${ }^{1}$ Institut de Ciències del Mar, CSIC, Pg. Marítim de la Barceloneta 37-49, 08003 Barcelona, Spain \\ ${ }^{2}$ Biology Department, Western Washington University, 518 High St., Bellingham, WA 98225, USA \\ ${ }^{3}$ Young Scientist Academy, 702 Paisley Court, Wilmington, NC 28409, USA \\ ${ }^{4}$ Sorbonne Université, CNRS-INSU, Laboratoire d'Océanographie de Villefranche, LOV UMR 7093, \\ 06230 Villefranche-sur-mer, France \\ ${ }^{5}$ Ocean and Earth Science, National Oceanography Centre, University of Southampton, European Way, \\ Southampton SO14 3ZH, UK
}

\begin{abstract}
As jellyfish interactions with humans increase in coastal waters, there is an urgent need to provide science-based management strategies to mitigate the negative socioeconomic impacts of jellyfish blooms and to exploit potential benefits of their ecosystem services. This Theme Section presents the latest advances in jellyfish research, from new sampling methods to food-web and life-cycle studies. The methodological advances presented will help to overcome difficulties in sampling due to the fluctuations in abundance and irregular distributions of jellyfish. The ecology of gelatinous species in marine food webs is explored through studying interactions between jellyfish and fish. Aspects of jellyfish life cycles, which often include both attached polyps and swimming medusae, are elucidated by locating the polyps and determining the factors that contribute to their success. Knowledge on all of these factors will be essential to understand the bloom dynamics of specific jellyfish groups.
\end{abstract}

KEY WORDS: Gelatinous zooplankton - Medusae $\cdot$ Ctenophores - Scyphistoma $\cdot$ Life cycle Population dynamics $\cdot$ Ecology $\cdot$ Food web $\cdot$ Fisheries

Research on gelatinous zooplankton (hereafter 'jellyfish') has burgeoned over the past decade. In particular, researchers are increasingly studying the impacts of nuisance outbreaks of jellyfish for human activities. Significant advances in jellyfish research are related to updated technology, molecular and predictive tools, and development of global databases on jellyfish (e.g. Jellyfish Database Initiative, Condon et al. 2014a). Recent studies have identified benefits of jellyfish for ecosystem services (e.g. fisheries) and have led to a greater appreciation by the wider scientific community of the significance of jellyfish in marine food webs and large-scale oceanic processes (e.g. the biological pump, Burd et al. 2016). This is clearly an exciting and challenging time for

*Corresponding author: vfuentes@icm.csic.es the jellyfish community to build on these discoveries by establishing new theories and paradigms at an ecosystem scale and to understand the natural and anthropogenic mechanisms driving fluctuations in jellyfish populations across multiple spatiotemporal scales.

Undoubtedly, the impetus for jellyfish research and the establishment of a multidecadal knowledge base on jellyfish ecology were stimulated from discussions and sentinel papers presented at the first 4 jellyfish symposia held in Gulf Shores, Alabama, USA, in 2000 (Purcell et al. 2001), Gold Coast, Queensland, Australia, in 2007 (Pitt \& Purcell 2009), Mar del Plata, Argentina, in 2010 (Purcell et al. 2012), and Hiroshima, Japan, in 2013 (Condon et al. 2014b). Atten-

(C) The authors 2018. Open Access under Creative Commons by Attribution Licence. Use, distribution and reproduction are unrestricted. Authors and original publication must be credited. 
dance and international participation has increased substantially across each symposium, enabling research priorities to be highlighted and new ideas and collaborations to be established.

The recent 5th International Jellyfish Bloom Symposium held at L'Aquàrium de Barcelona, Spain, from 30 May to 3 June 2016 had a record 208 participants from 37 countries. Along the coast of Spain and in the greater Mediterranean Sea, major problems with jellyfish have occurred for at least 2 decades and have greatly impacted tourism and other ecosystem services. To enhance management approaches and mitigation measures against these impacts, the MedJellyRisk project was established in the Western Mediterranean (Italy, Spain, Malta, Tunisia) in 2012. Hence, Barcelona was an ideal location for the symposium.

The studies presented in this Theme Section cover the latest advances in jellyfish research. Purcell's (2018) review on Aequorea spp. illustrates many approaches to research on jellyfish ecology. Other methods advancing jellyfish research include the use of drones to survey blooms (Schaub et al. 2018) and the use of statocysts to age jellyfish (Heins et al. 2018). Fisheries bycatch data provided invaluable insight into distributions of fish and jellyfish in Decker et al. (2018) and Aleksa et al. (2018), and by-caught fish served as samplers of ctenophores in Eriksen et al. (2018). Trophic overlap between fish and jellyfish was evaluated by Tilves et al. (2018). The environmental effects on asexual reproduction by scyphozoan polyps were studied in the laboratory (Feng et al. 2018a, Treible et al. 2018) and in situ (Feng et al. 2018b, Hočevar et al. 2018). Henschke et al. (2018) developed a bioenergetics-based population model using both the benthic and pelagic stages of Aurelia spp. The potential location of polyps was deduced from the earliest pelagic stages in Dong et al. (2018). Molecular tools described how jellyfish populations were structured geographically (Abboud et al. 2018). Potential effects of diverse factors on medusa population composition and distribution were tested, with factors including hurricanes (Bologna et al. 2018), pycnoclines (Suzuki et al. 2018), wind (Pires et al. 2018), dam-controlled water flow (Amorim et al. 2018), fish farms (Halsband et al. 2018), and Arctic ice (Purcell et al. 2018). How environmental factors and swimming ability may determine distributions of cubozoans was investigated by Schlaefer et al. (2018).

We dedicate this Theme Section to our friend and colleague, Mary Arai, who was a leader in our field and passed away in 2017 (see 'In Memoriam', this Theme Section).
Acknowledgements. We thank everyone involved in organizing the 5th International Jellyfish Bloom Symposium, from which most of the articles in this Theme Section originated, especially the Local Scientific Committee from the Institut de Ciències del Mar (CSIC, Barcelona, Spain): V. Fuentes, M. Acevedo, M. Gentile, R. Golo, M. Marambio, L. López, M. Pascual, U. Tilves.

\section{LITERATURE CITED}

Abboud SS, Gómez Daglio L, Dawson MN (2018) A global estimate of genetic and geographic differentiation in macromedusae-implications for identifying the causes of jellyfish blooms. Mar Ecol Prog Ser 591:199-216

Aleksa KT, Nero RW, Wiggert JD, Graham WM (2018) Descriptive density models of scyphozoan jellyfish in the northern Gulf of Mexico. Mar Ecol Prog Ser 591:71-85

Amorim K, Mattmüller RM, Algueró-Muñiz M, Meunier CL and others (2018) Winter river discharge may affect summer estuarine jellyfish blooms. Mar Ecol Prog Ser 591: 253-265

Bologna P, Gaynor JJ, Meredith R, Restaino D, Barry C (2018) Stochastic event alters gelatinous zooplankton community structure: impacts of Hurricane Sandy in a Mid-Atlantic estuary. Mar Ecol Prog Ser 591:217-227

*Bosch-Belmar M, Milisenda G, Girons A, Taurisano V and others (2017) Consequences of stinging plankton blooms on finfish mariculture in the Mediterranean Sea. Front Mar Sci 4:240

* Burd AB, Buchan A, Church M, Landry M and others (2016) Towards a transformative understanding of the biology of the ocean's biological pump: priorities for future research. Report of the NSF Biology of the Biological Pump Workshop, February 19-20, 2016 (Hyatt Place New Orleans, New Orleans, LA)

Condon $\mathrm{RH}$, Lucas $\mathrm{CH}$, Duarte CM, Pitt KA and others (2014a) Jellyfish Database Initiative (JeDI). www.bcodmo.org/dataset/526852

* Condon RH, Lucas CH, Pitt KA, Uye SI (2014b) Jellyfish blooms and ecological interactions. Mar Ecol Prog Ser 510:109-128

*Decker MB, Robinson KL, Dorji S, Cieciel KD, Barceló C, Ruzicka JJ, Brodeur RD (2018) Jellyfish and forage fish spatial overlap on the eastern Bering Sea shelf during periods of high and low jellyfish biomass. Mar Ecol Prog Ser 591:57-69

* Dong J, Wang B, Duan Y, Yoon WD and others (2018) Initial occurrence, ontogenic distribution-shifts and advection of Nemopilema nomurai (Scyphozoa: Rhizostomeae) in Liaodong Bay, China, from 2005-2015. Mar Ecol Prog Ser 591:185-197

* Eriksen E, Bogstad B, Dolgov A, Beck IM (2018) Cod diet as an indicator of Ctenophora abundance dynamics in the Barents Sea. Mar Ecol Prog Ser 591:87-100

*Feng S, Lin J, Sun S, Zhang F, Li C (2018a) Hyposalinity and incremental micro-zooplankton supply in earlydeveloped Nemopilema nomurai polyp survival, growth, and podocyst reproduction. Mar Ecol Prog Ser 591: $117-128$

Feng S, Wang SW, Sun S, Zhang F, Zhang GT, Liu MT, Uye S (2018b) Strobilation of three scyphozoans (Aurelia coelurea, Nemopilema nomurai, and Rhopilema esculentum) in the field at Jiaozhou Bay, China. Mar Ecol Prog Ser 591:141-153 
Halsband C, Majaneva S, Hosia A, Emaus PA and others (2018) Jellyfish summer distribution, diversity and impact on fish farms in a Nordic fjord. Mar Ecol Prog Ser 591:267-279

Heins A, Sötje I, Holst S (2018) Assessment of investigation techniques for scyphozoan statoliths, with focus on early development of the jellyfish Sanderia malayensis. Mar Ecol Prog Ser 591:37-56

Henschke N, Stock CA, Sarmiento JL (2018) Modeling population dynamics of scyphozoan jellyfish (Aurelia spp.) in the Gulf of Mexico. Mar Ecol Prog Ser 167-183

Hočevar S, Malej A, Boldin B, Purcell JE (2018) Seasonal fluctuations in population dynamics of Aurelia aurita polyps in situ with a modelling perspective. Mar Ecol Prog Ser 591:155-166

Pires RFT, Cordeiro N, Dubert J, Marraccini A, Relvas P, dos Santos A (2018) Untangling Velella velella (Cnidaria: Anthoathecatae) transport: a citizen science and oceanographic approach. Mar Ecol Prog Ser 591:241-251

Pitt KA, Purcell JE (eds) (2009) Jellyfish blooms: causes, consequences, and recent advances. Developments in Hydrobiology 206. Springer, Dordrecht

Purcell JE (2018) Successes and challenges in jellyfish ecology: examples from Aequorea spp. Mar Ecol Prog Ser 591:7-27

Purcell JE, Graham WM, Dumont H (eds) (2001) Jellyfish blooms: ecological and societal importance. Developments in Hydrobiology 155. Kluwer Academic Publish- ers, Dordrecht

*Purcell JE, Mianzan H, Frost JR (eds) (2012) Jellyfish blooms IV: interactions with humans and fisheries. Developments in Hydrobiology 220. Springer, Dordrecht

* Purcell JE, Juhl AR, Mańko MK, Aumack CF (2018) Overwintering of gelatinous zooplankton in the coastal Arctic Ocean. Mar Ecol Prog Ser 591:281-286

Schaub J, Hunt BPV, Pakhomov EA, Holmes K, Lu Y, Quayle L (2018) Using unmanned aerial vehicles (UAVs) to measure jellyfish aggregations. Mar Ecol Prog Ser 591: $29-36$

Schlaefer JA, Wolanski E, Kingsford MJ (2018) Swimming behaviour can maintain localised jellyfish (Chironex fleckeri: Cubozoa) populations. Mar Ecol Prog Ser 591: 287-302

Suzuki KS, Niida Y, Tsubono T, Takimoto H, Kumakura E, Ishii H, Nogata Y (2018) Mechanisms underlying heterogeneous distribution of moon jellyfish Aurelia aurita s.l. across a sharp pycnocline. Mar Ecol Prog Ser 591:229-239

* Tilves U, Fuentes VL, Milisenda G, Parrish CC, Vizzini S, Sabatés A (2018) Trophic interactions of the jellyfish Pelagia noctiluca in the NW Mediterranean: evidence from stable isotope signatures and fatty acid composition. Mar Ecol Prog Ser 591:101-116

* Treible LM, Pitt KA, Klein SG, Condon RH (2018) Exposure to elevated $p \mathrm{CO}_{2}$ does not exacerbate reproductive suppression of Aurelia aurita jellyfish polyps in low oxygen environments. Mar Ecol Prog Ser 591:129-139 